\title{
El pasado remasterizado: la posproducción del patrimonio cultural de México
}

\author{
Remastering the Past: the Post-production of Mexico's Cultural Heritage \\ Leticia Flores Farfán y Sandra L. López Varela \\ Universidad Nacional Autónoma de México \\ leticiafloresfarfan@gmail.com
}

\begin{abstract}
Resumen
A 50 años de la masacre del 2 de octubre de 1968 en el Conjunto Habitacional Nonoalco Tlatelolco, el jefe de gobierno de la Ciudad de México, José Ramón Amieva, firmó un mandato en el que declaraba Tlatelolco como patrimonio cultural intangible, en reconocimiento a los acontecimientos históricos ocurridos ahí, desde su fundación por los aztecas en 1337. En su discurso Amieva dejó claro que los sucesos del 2 de octubre de 1968 formaban parte de la declaratoria, al enfatizar que no se iba a permitir nunca más que un estudiante fuera víctima de agresión, mucho menos desconocer su paradero. Insertar los eventos de 1968 dentro de una declaratoria de patrimonio cultural intangible articula una nueva verdad nacional de la masacre. Esta incorporación gubernamental del acontecimiento dentro de la ahora historia de la izquierda mexicana triunfante puede difuminar su particularidad y su carácter subversivo; de ahí, que algunas voces han alertado sobre ese peligro y apostado por una concepción contracultural del patrimonio para mantener vivo y visible el reclamo de justicia social propio del movimiento del 68.
\end{abstract}

Palabras clave: patrimonio, memoria, movimientos sociales, 1968, México

\begin{abstract}
On the wake of the fiftieth anniversary of the student's massacre that took place on October 2, 1968, at the Nonoalco Tlatelolco Housing Complex, José Ramón Amieva, Mexico City’s major, signed a mandate whereby "Tlatelolco" became part of the intangible cultural heritage to honor its historical richness, dating back to its foundation by the Aztecs in 1337. In his speech, Amieva emphasized no student would be allowed to be the victim of such an act of aggression, much less his or her whereabouts be unknown. By inserting the massacre of 1968 within the declaration of intangible cultural heritage, the government created a "new" national truth regarding the massacre, with the potential to blur the character of the 1968 movement; not without inciting a countercultural movement introducing an alternative view of Mexico's heritage, which visibly brings to life a claim for social justice.
\end{abstract}

Keywords: heritage, memory, social movements, 1968, Mexico

Fecha de recepción: 01 de agosto de 2019 | Fecha de aceptación: 16 de enero de 2020

Cómo citar este artículo (MLA): Flores Farfán, Leticia y Sandra L. López Varela. "El pasado remasterizado: la posproducción del patrimonio cultural de México". Estudios del Discurso 6.1 (2020): 82-103. 
El pasado remasterizado: la posproducción del patrimonio cultural de México

\section{Introducción}

1968 Kennedy y del reverendo Martin Luther King Jr., figura clave del movimiento de los Derechos Civiles de Estados Unidos. Este año fue testigo de la propagación del malestar social y racial contra los regímenes autoritarios y el conservadurismo social. Los movimientos antibélicos tomaron las calles para protestar contra el imperialismo estadounidense y con ello el colonialismo europeo se hizo también evidente. Los escritos de filósofos marxistas como Herbert Marcuse, Ernst Bloch, Jean Paul Sartre y Simone de Beauvoir nutrían la mirada crítica que cuestionaba las políticas conservadoras de De Gaulle y su creciente centralización del poder. La sociedad crítica de 1968 ponía en duda que el capitalismo hubiera contribuido al crecimiento económico en el mundo. En ese escenario político se abrió un campo de posibilidades y cambios, que instaban a la libertad de expresión y la lucha por los derechos de las mujeres. Incluso, el pensamiento crítico también se manifestó en las artes. Los intelectuales involucrados en el movimiento como Allen Ginsberg y William Burroughs, crearon el movimiento literario Beat y exploraron la cultura y la política estadounidenses. El movimiento contracultural enfrentó, por medio de objetos de uso cotidiano de la sociedad norteamericana, el conservadurismo de las artes visuales, como lo hizo Warhol con sus cajas de "Brillo". Por su parte, en la música, los sonidos ondulantes de Born to be Wild, de Steppen-wolf, las letras provocativas de Jumpin' Jack Flash, de los Rolling Stones, y las canciones de paz y amor de los Beatles o Janis Joplin, iban cargadas de ritmos políticos. Y aquellas voces "insurgentes", "anarquistas" o "comunistas" también resonaron en Alemania, Checoslovaquia, Italia, Canadá y México (López Varela, When your country).

Como parte de este escenario, el descontento hacia el autoritarismo de De Gaulle terminó en violentos enfrentamientos entre los estudiantes y la policía, como fueron los sucesos ocurridos en París, en mayo de 1968. Los estudiantes organizaron el cierre de la Universidad de Nanterre y de la Sorbona como protesta en contra de la política educativa nacional, que dejaba a los estudiantes sin oportunidades de empleo, o bien, como asistentes de profesor con inciertas 
perspectivas profesionales. La evacuación de la Sorbona por parte de las fuerzas policiales se tornó violenta, lo que incitó a una huelga general a nivel nacional de la clase obrera, que se unió al movimiento estudiantil. Posterior a estos eventos, las protestas masivas y las trifulcas en las calles se manifestaban contra la hipocresía detrás del crecimiento económico y contra el conservadurismo social y el imperialismo. Para los gobiernos conservadores, estas voces ilustraban la perniciosa propagación del comunismo y el anarquismo en el mundo.

Por desgracia, esa postura crítica de 1968 hizo que se desplegara la presencia intimidatoria de las fuerzas armadas por las calles de muchas ciudades en el mundo, entre ellas Chicago y Praga, las cuales invadieron las plazas públicas con gases lacrimógenos, tanques y ametralladoras. La Ciudad de México no fue una excepción (figura 1). Diez días antes de la inauguración de los Juegos Olímpicos de 1968, en la Ciudad de México, un número desconocido de estudiantes, que protestaban contra el régimen autoritario mexicano en Tlatelolco, fueron brutal y cobardemente masacrados en aquel mercado al aire libre, donde el conquistador

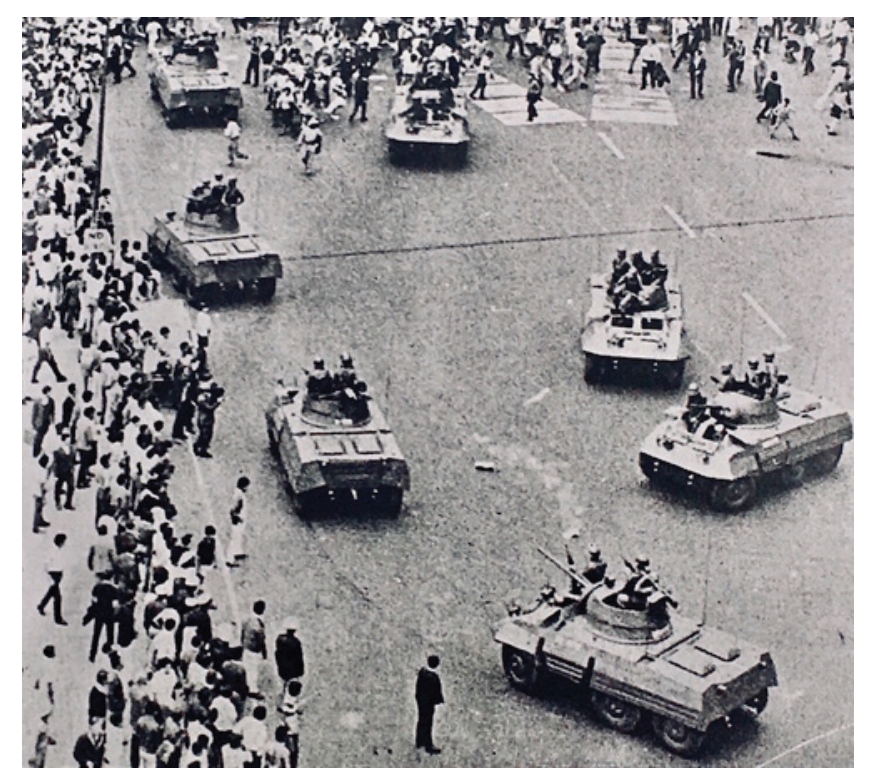

Figura 1. La intimidante presencia del ejército y la policía en la Ciudad de México a pocos meses de los Juegos Olímpicos de 1968. Fotografías públicas de la exposición del archivo María y Héctor García en el Bosque de Chapultepec, en la Ciudad de México en 2018. Fotografía de Sandra L. López Varela. 
El pasado remasterizado: la posproducción del patrimonio cultural de México

Pedro de Alvarado se enfrentó a los aztecas el 13 de agosto de 1521 (López Varela, When your country). ¿Cuáles fueron los sucesos que llevaron al gobierno mexicano a tener esta atroz respuesta y a declarar este terrible acontecimiento como patrimonio intangible cincuenta años después?

\section{México 1968}

Hacia finales de la década de 1960, la postura política e intelectual que prevalecía en Europa y Estados Unidos se había propagado hacia América Latina. En 1968, buena parte de la sociedad mexicana se veía atraída por esa postura crítica que se desarrollaba en "occidente", analizando de manera particular la existente injusticia social en el país, las condiciones laborales de su clase obrera y apoyaba el cuestionamiento mundial sobre los intereses capitalistas detrás de la guerra de Vietnam. El movimiento estudiantil mexicano de 1968 llevó a las calles aquellas ideas que el mundo entero compartía para impugnar el autoritarismo del partido gobernante y de los muchos cánones dictados por una sociedad tradicional. Para 1968 el Partido Revolucionario Institucional (PRI) había gobernado a México y a su tradicional sociedad católica durante casi cuatro décadas. Calificado por algunos politólogos como la "dictadura perfecta", el Partido siguió gobernando a México hasta el año 2000 cuando asumió el gobierno el Partido Acción Nacional (PAN).

¿Quién habría podido imaginar que una rencilla entre estudiantes de la Ciudad de México terminaría en un enfrentamiento público, que iba a suscitar una enérgica reacción del gobierno y se convertiría en una pesadilla política a pocos meses del inicio de las Olimpiadas? La postura crítica por parte del movimiento estudiantil que se encontraba en las calles no fue bien recibida por el gobierno de Díaz Ordaz, quien pretendía poner a México en el mapa con el desarrollo de los Juegos Olímpicos en octubre de 1968. La clase obrera mexicana se unió a los estudiantes para organizar un movimiento de resistencia contra el gobierno del entonces presidente Díaz Ordaz, quien dejó en claro que iba a restablecer el orden, a cualquier precio. Y, cumpliendo su palabra, el 18 de septiembre el ejército ocupó el campus de Ciudad Universitaria, arrestando a casi mil estudiantes, justo enfrente del 
Estadio Olímpico, donde se celebraría la ceremonia de inauguración de los Juegos Olímpicos.

En respuesta, los líderes del movimiento estudiantil convocaron a una reunión en Tlatelolco, el 2 de octubre de 1968. Cerca de diez mil estudiantes respondieron al llamado, llenando la Plaza de las Tres Culturas. Los estudiantes, una generación joven y crítica, armados pacíficamente con altavoces, se manifestaban contra el gobierno, sin saber que estaban rodeados por las fuerzas militares y policiales. A las 18:10 horas, el cielo se iluminó con las luces de bengala verdes lanzadas por un helicóptero que sobrevolaba la plaza. En cuestión de segundos, el escalofriante sonido de las balas reveló que les habían tendido una emboscada. En lugar de llamar al diálogo, el presidente Díaz Ordaz puso en acción todo su poder. Ubicados en los techos de los edificios circundantes, francotiradores expertos dispararon indiscriminadamente contra la multitud en la plaza, incluidos los niños. Para disfrazar su responsabilidad las fuerzas armadas incluso dispararon contra los suyos, justificando así que habían sido atacadas por una sociedad civil que, sin embargo, aun hoy en día no tiene fácil acceso a las armas. Los sobrevivientes fueron llevados a un lugar desconocido para "examinarlos". Muchos nunca regresaron. Al amanecer, la versión oficial encubrió la masacre, no sólo retirando rápidamente los cadáveres y a los heridos, sino también con la publicación de breves titulares y notas sobre el enfrentamiento entre la policía y los estudiantes en Tlatelolco.

\section{En busca de la verdad}

Pocos días después de que el movimiento fuera brutalmente aplastado, México escribió un nuevo capítulo en su historia, al convertirse en el primer país latinoamericano que albergara los Juegos Olímpicos. El mundo apenas recuerda lo que sucedió diez días antes de la inauguración de las Olimpiadas de 1968 en la Ciudad de México. Quizá recuerde la declaración política contra la discriminación racial expresada por los atletas afroestadounidenses, John Carlos y Tommie Smith, cuando recibieron sus medallas de oro y de bronce tras ganar la carrera de 200 metros. Mientras el himno nacional de Estados Unidos sonaba en el estadio, los atletas, 
El pasado remasterizado: la posproducción del patrimonio cultural de México

que había subido al podio descalzos, levantaron el puño portando un guante negro, al tiempo que inclinaban la cabeza. Los "niños de 1968" (Deleuze y Guattari) habían perdido su causa y no podrían continuar la lucha. El movimiento había terminado y, a partir de ahí, el miedo y la apatía se apoderaron del mundo entero. Cincuenta años después, nadie sabe con exactitud qué sucedió ese día y ningún culpable ha sido llevado ante la justicia. La "Operación Silencio", la contrainsurgencia contra las "fuerzas oscuras" de "intereses desconocidos", incluyó la destrucción y ocultamiento de documentación impresa y visual, e incluso el encarcelamiento, desaparición y asesinato de los opositores, en aras de proteger la democracia y la estabilidad social (Casas y Flores Farfán 202). Tras el ocultamiento y distorsión de los hechos, y con el apoyo de los medios de comunicación y la sociedad conservadora de México, el gobierno, el ejército y la policía terminaron apareciendo como las víctimas de las acciones "criminales" de los "agresores".

Incluso en sus últimos días, el presidente Díaz Ordaz insistió en que "los agitadores", si no "los comunistas", habían estado a punto de tomar el Palacio Nacional de Gobierno y la Secretaría de Relaciones Exteriores, a pocos días de la inauguración de los Juegos Olímpicos. Por ello, habían sido arrestados y llevados a un campamento militar para ser interrogados. Sin embargo, al examinar sus cuerpos, los "alborotadores" y los soldados presentaban heridas de balas con trayectorias verticales, lo que significa que los "idealistas" habían utilizado ametralladoras y comenzaron a disparar desde los techos de los edificios que flanqueaban la plaza. Díaz Ordaz sostenía que "los que murieron ese día fueron asesinados por sus propios compañeros" (Krauze). El Presidente nunca expresó ningún remordimiento, aunque llegó a aceptar que "fue una tragedia en la historia del país". Sin embargo, insistía en que esos jóvenes, influidos por ideas extranjeras, querían un México diferente, que a nadie favorecía (Casas y Flores Farfán).

Pero no todos cayeron en el desánimo. Quienes buscaban la verdad escribieron numerosos ensayos (González de Alba; Poniatowska), recopilaron testimonios y localizaron archivos gráficos (Scherer García y Monsiváis; Monsiváis; Montemayor), produjeron documentales y películas, incluso películas de ficción (Casas y Flores Farfán). En 1993, durante el mandato del presidente Salinas de Gortari, se colocó en la plaza principal de Tlatelolco una estela con los nombres de veinte víctimas y un poema de Rosario Castellanos, 
una distinguida voz literaria (figura 2). Todos los años, quienes recuerdan a las víctimas visitan la estela para "conmemorar" lo que sucedió aquella fatídica tarde de octubre en la Plaza de las Tres Culturas, dejando flores y encendiendo velas. Su ritual anual llega hasta el Palacio Nacional, con una marcha desde Tlatelolco para exigir justicia, en donde los asistentes, corean la consigna: “ $i 2$ de octubre, no se olvida!”

En 2002, el presidente Vicente Fox ordenó que se constituyera la Fiscalía Especial para Movimientos Sociales y Políticos del Pasado (Diario Oficial de la Federación, Acuerdo) a fin de conocer la verdad sobre lo ocurrido en 1968 y llevar a los responsables ante la justicia (Casas y Flores Farfán). La Fiscalía Especial determinó que las órdenes y acciones llevadas a cabo por los presidentes Gustavo Díaz Ordaz y Luis Echeverría Álvarez, que en 1968 fuera secretario de Gobernación,

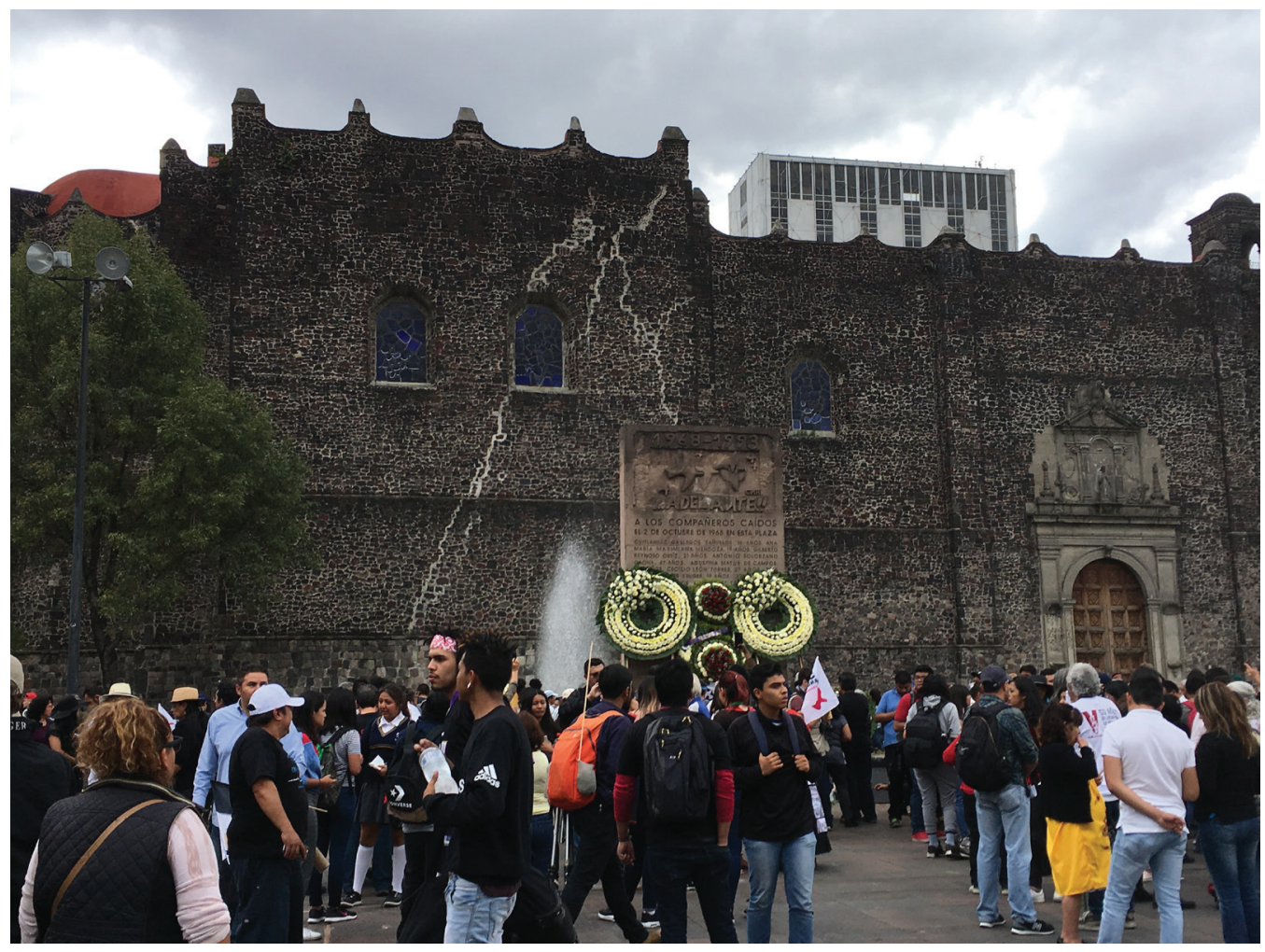

Figura 2. En 1993, durante el mandato del presidente Salinas de Gortari, se colocó una estela en Tlatelolco que registra el nombre de las 20 víctimas que según el gobierno perecieron el 2 de octubre de 1968. Fotografía de Sandra L. López Varela. 
debían ser investigadas. El informe concluyó que el gobierno había considerado a la insurgencia como un enemigo ideológico del Estado y que al reprimirla había incurrido en crímenes de lesa humanidad, en clara violación de la Ley Internacional sobre Derechos Humanos (Oficina del Fiscal Especial Ignacio Carrillo Prieto). Sin embargo, a pesar de dicha investigación, a la fecha nadie ha sido llevado ante la justicia.

El recuerdo de lo que pasó ese día quizá siga siendo encubierto. Sin embargo, cuando una comunidad ha sido víctima de actos criminales, arbitrarios e injustos, su instinto inmediato es proteger su propia memoria, erigiendo monumentos o realizando actos conmemorativos. Para demostrar que las víctimas nunca serán olvidadas, cincuenta años después, el 2 de octubre de 2018, noventa mil personas acudieron a la plaza, en el centro de la Ciudad de México, llevando sus recuerdos de aquellos hechos y de las víctimas masacradas ese día (figura 3). ¡La "Operación

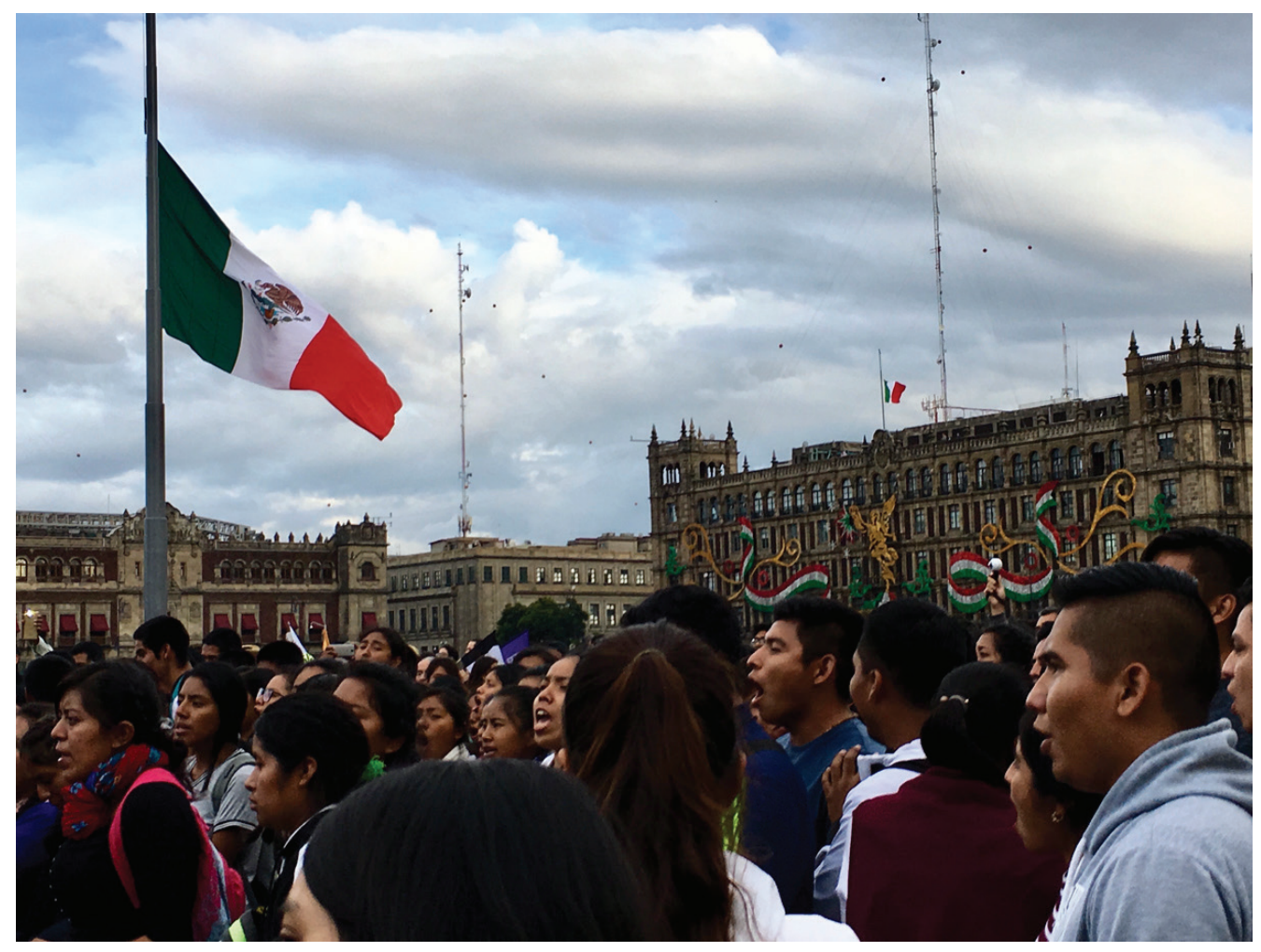

Figura 3. El 2 de octubre de 2018, casi noventa mil personas marcharon por las calles de la Ciudad de México para recordar el 50 aniversario luctuoso de aquella fatídica tarde en Tlatelolco. Fotografía de Sandra L. López Varela. 
Silencio", les ha fallado a los regímenes autoritarios. De hecho, es por esto que traemos a Tzvetan Todorov a nuestra discusión, pues sus escritos han hecho un análisis profundo y audaz de las estrategias mediante las cuales los regímenes autoritarios destruyen, desaparecen y alteran la memoria, para así conducir la construcción de una memoria oficial.

\section{La creación de militantes y antimilitantes de la memoria}

Tzvetan Todorov, mejor conocido por su análisis sobre los crímenes históricos cometidos durante la Conquista del Nuevo Mundo, abordó en sus últimas obras el debate entre memoria e historia (Todorov) iniciado previamente por Pierre Nora y Maurice Halbwachs. De hecho, el enfoque de Todorov sobre la memoria colectiva e individual tal vez no parezca muy diferente del concepto de Halbwachs de una memoria socialmente mediada, siempre vinculada a un grupo, que concibe una imagen unificada del pasado.

A primera vista, podría pensarse que Todorov no tiene nada significativo que añadir a la "arqueología de la memoria". Sin embargo, lo que hace única la propuesta de Todorov es su enfoque atrevido que define el proceso por el cual las sociedades recuerdan y olvidan, a pesar de que no logra desentrañar enteramente la relación entre memoria y cultura. Más bien, el interés de Todorov radica en analizar las formas en que un individuo percibe, recuerda, olvida y reinterpreta un evento lo que coincide con teorías anteriores que abordan la forma en que la sociedad recuerda (Connerton). La idea de Todorov de que la construcción individual de la memoria puede ser un acto consciente o inconsciente, a través de la experiencia de eventos placenteros o dolorosos que han tenido lugar a lo largo de la vida de una persona, nos recuerda el análisis posterior de Misztal sobre cómo se generan, mantienen y reproducen las representaciones del pasado a través de textos, imágenes, sitios, rituales, acciones y experiencias.

Precisamente, el interés de Todorov (Mémoire du mal), y el nuestro también, consiste en analizar cómo abusan de estos "testigos" de la memoria pública los regímenes totalitarios. Es decir, el interés primordial de Todorov es analizar cómo 
El pasado remasterizado: la posproducción del patrimonio cultural de México

los textos, las placas, los ritos o los monumentos han sido utilizados para construir la memoria con "propósitos nobles e innobles". El abuso de la memoria se da cuando ésta es objetivada, es decir, cuando está ligada al pasado a través de un objeto, que conmemora una versión literal y parcial de la memoria, ya que ese tipo de memoria nunca dejará lecciones valiosas para el presente (Todorov, Mémoire du mal), como lo ha sido el erigir la estela conmemorativa del 25 aniversario de la masacre en Tlatelolco (figura 2) en donde aparecen los nombres de una veintena de estudiantes -las únicas víctimas reconocidas oficialmente que perdieron la vida el 2 de octubre. La estela se encuentra en total abandono durante todo el año, salvo cuando se "conmemora" el aniversario luctuoso 2 de octubre.

\section{Remasterizar el pasado}

A pesar de que México cuenta con una de las legislaciones más antiguas para la preservación de sus monumentos arqueológicos (Schroeder Cordero 672) y de adherirse a las políticas de la unesco, la Ley Federal de Monumentos y Zonas Arqueológicos, Artísticos e Históricos, el ordenamiento vigente para la protección de estos bienes nacionales, desde su promulgación por el Presidente Luis Echeverría Álvarez el 28 de abril de 1972, las modificaciones no han incorporado la definición de patrimonio cultural, mucho menos los conceptos de tangible o intangible, términos que ya dejó de utilizar la UNESCO desde 2014. En su Artículo 20, sólo se hace referencia al mandato del Instituto Nacional de Antropología e Historia y del Instituto Nacional de Bellas Artes y Literatura de proteger el patrimonio cultural de la nación y en su Artículo $3^{\circ}$, a la existencia de un Secretario del Patrimonio Cultural, nombrado en su momento, mas no por los subsecuentes gobiernos federales.

Es posible asumir que el patrimonio cultural que hay que preservar está constituido por sólo tres tipos de bienes: arqueológicos, artísticos e históricos. Estos bienes imprescriptibles e inalienables son declarados monumentos con base en su contribución a la historia de la nación mexicana. Los monumentos arqueológicos son el producto de las culturas que habitaban el territorio mexicano antes de la Conquista española. Los monumentos históricos son bienes relacionados con la historia de la 
nación, que "prescribiô" en el siglo xIx. De su historia moderna, México protege sólo aquellos monumentos que posean un valor estético relevante. En 2014, incluso la UNESCO (Indicadores 130) aceptó que todo enfoque que mire exclusivamente hacia el pasado corre el riesgo de convertir el patrimonio en una entidad fija y congelada, que pierde relevancia tanto para el presente como para el futuro. Es más, UNESCO (Indicadores 132) ha tenido que actualizar recientemente su concepción de patrimonio cultural "para promover la paz y el desarrollo social, ambiental y económico sostenible". Sin embargo, los curadores de los monumentos nacionales no han adoptado esta definición que señala que, "El patrimonio cultural en su más amplio sentido es a la vez un producto y un proceso que suministra a las sociedades un caudal de recursos que se heredan del pasado se crean en el presente y se transmiten a las generaciones futuras para su beneficio" (UNESCO, Indicadores 132).

Si bien es cierto que el patrimonio intangible no se encuentra definido en la legislación federal, los curadores reconocen que nuestros antepasados no sólo nos heredaron monumentos y colecciones de objetos, también nos dejaron tradiciones orales, prácticas sociales, rituales, conocimientos y habilidades para producir artesanías tradicionales y conocimientos sobre la naturaleza y el universo (UNESCO, Textos básicos). Entones, ¿por qué declarar a Tlatelolco patrimonio intangible? Consideramos que su proximidad al sitio arqueológico de Tlatelolco es la única explicación para que se haya dado "este abuso de la memoria", que implica considerar los hechos ocurridos ese 2 de octubre de 1968 como parte del patrimonio intangible de México en el discurso de Amieva.

Pero el hecho de que se declararan los acontecimientos de 1968 en Tlatelolco como patrimonio intangible no fue un acto neutral por parte del gobierno de la Ciudad de México. Se trata de una estrategia alineada a los intereses de los vencedores de las batallas sociales, que están decididos a dictar la narrativa del relato oficial del 2 de octubre de 1968, para crear una memoria colectiva que formará parte de una historia monolítica e inmutable, que emana de una idea imprescriptible de patrimonio cultural, que siempre ha prevalecido en México y que ha llevado a sus curadores a caer en la trampa de que el deber de recordar impone la exigencia irrevocable de defender los derechos imprescriptibles de la memoria (Todorov, Mémoire du mal). Mas esta militancia por parte de los curadores del patrimonio cultural tiene sus razones y tiene que ver con el mandato federal que 
El pasado remasterizado: la posproducción del patrimonio cultural de México

confiere a la conformación de la disciplina arqueología como parte indisoluble de la conciencia histórica nacional (López Varela, La herencia).

\section{Patrimonio intangible o el abuso de la memoria}

Hay que prestar atención a las reflexiones que Todorov (Les abus) hiciera sobre los abusos de la memoria que se suceden por parte del Estado dado que ellos obstruyen la memoria ejemplar y su sentido de la justicia, con lo que se acota la posibilidad de aprender de las injusticias del pasado para evitar que ocurran en el presente (Todorov, Les abus).

La estrategia del gobierno, basada en la creencia de que el preservar las memorias del pasado a partir de monumentos garantiza su virtud, ha fracasado con los antimonumentos. La colocación de antimonumentos por parte de la sociedad en el espacio público es un uso ejemplar de la memoria. Todorov (Les abus) diría que las creencias y valores de quienes han colocado estos monumentos nunca serán sometidas a un uso literal de la memoria. Sin embargo, la mayoría de la gente ignora dónde se encuentra la placa que honra al rector Javier Barros Sierra por su valor al encabezar una marcha masiva desde la UNAm hasta el centro de la Ciudad de México y por su defensa de la autonomía de la Universidad, que había sido violada por las fuerzas militares que atacaron una de sus escuelas en 1968. Sin embargo, la gente está protegiendo los eventos que han ocurrido en su vida y los preserva como memoria social.

No estamos en contra de que se erijan monumentos mnemotécnicos que ayuden a relacionar espacios con acontecimientos, siempre y cuando éstos conduzcan a la búsqueda de la verdad y la justicia (Flores Farfán). Lo que debemos vigilar y contra lo que debemos oponernos es al abuso que puede producirse al levantar monumentos para construir una verdad oficial de los acontecimientos -al remasterizar el pasado para "mejorar su imagen". Más bien estamos en contra de que se objetive la atrocidad de Tlatelolco como patrimonio intangible, como una forma de tranquilizar a los protagonistas para que permanezcan en el papel de héroes o víctimas. Teniendo el control de la memoria, la historia monolítica que creó el 
gobierno con "fines nobles" o "innobles", llevará a que sus entusiastas defensores quieran mantenerla viva, creando un sentido del deber hacia esa memoria al convertirse en "militantes de esa memoria".

La "posproducción" de este evento, el equiparar la masacre de Tlatelolco con el concepto de patrimonio intangible, provee al "espectador" con información errónea sobre lo que ocurrió el 2 de octubre de 1968. El declarar Tlatelolco como patrimonio intangible es un ejemplo clásico de lo que Laurajane Smith (¿Gestos vacíos? 161) denomina una "tecnología de gobierno", con base en la tesis de Foucault sobre la "gubernamentalidad". El declarar esta masacre como patrimonio intangible, es decir, como parte de las "tradiciones o expresiones vivas que hemos heredado de nuestros antepasados y que serán transmitidas a nuestros descendientes" (UNEsCo Textos básicos), sólo puede ser una estrategia que despliega el Estado para ayudar a los políticos y a los legisladores a interpretar, entender, regular y gobernar las demandas y reclamos por hechos del pasado.

Nadie pone en duda que en torno a la Unidad Habitacional Nonoalco Tlatelcolco existan tradiciones orales, espectáculos, rituales y festividades; se generen conocimientos y prácticas relativos a la naturaleza y el universo; y se reproduzcan saberes y técnicas vinculados a la artesanía tradicional -todos estos elementos de la definición de patrimonio intangible. Sin embargo, el hecho de reducir la masacre a un conjunto de criterios internacionales, ajustados para que quepan en la historia nacional de México y que el público los preserve en la memoria colectiva, puede inducir a que la memoria caiga en un olvido más profundo que el que buscaban las acciones del gobierno al controlar, ocultar y destruir documentos y testimonios. La institucionalización de la masacre como monumento inscrito en las páginas de la historia oficial de México ensombrece el carácter opositor y disidente del movimiento estudiantil de 1968, mitigando sus efectos críticos. Mediante la operación del "patrimonio" (Wilson 822), se difumina la pérdida de vidas humanas que fueron eliminadas por ser críticas del régimen autoritario del presidente Díaz Ordaz y el conservadurismo social.

¿Debemos aceptar sin resistencia que la masacre de estudiantes en 1968 renazca ahora en la cuna de la historia mexicana como patrimonio cultural intangible? La respuesta la ha dado la ciudadanía el 2 de octubre de 2018, al romper el marco conceptual de la plaza principal del centro de la Ciudad de México, en donde el 
entorno de edificaciones codifica las tensiones de la Conquista y la resistencia, colocando un "antimonumento" que evidencia que la selección de eventos que se hizo para construir una verdad oficial de la desaparición de los estudiantes no ha sido aceptada (figura 4).

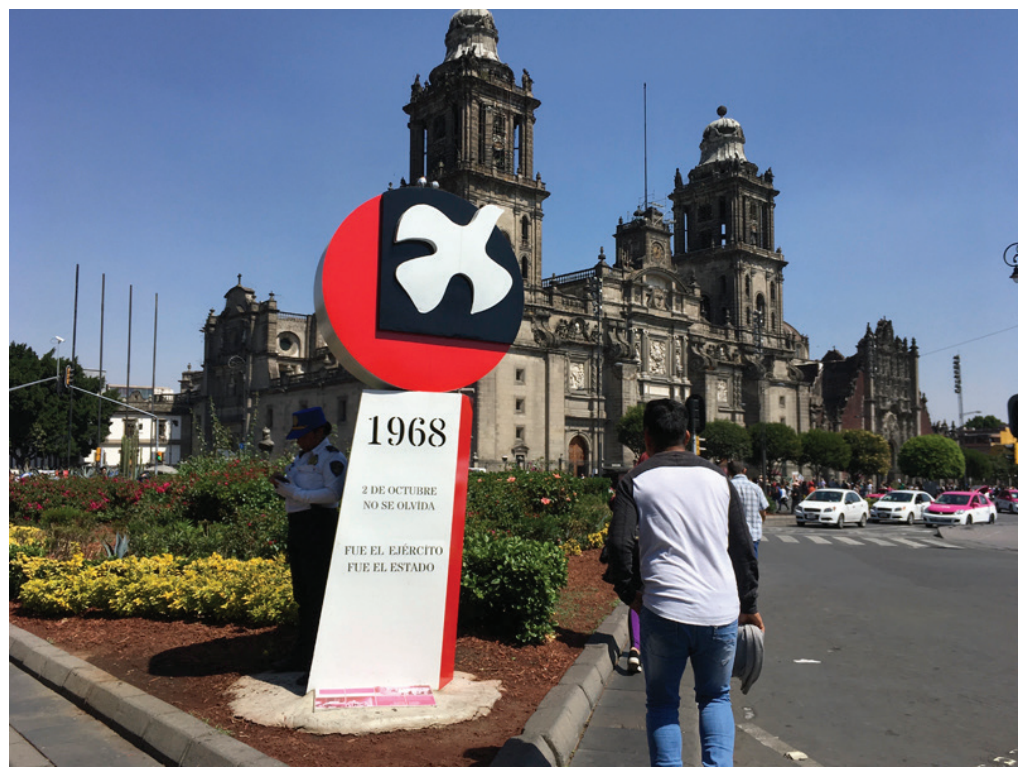

Figura 4. El 2 de octubre de 2018, la paloma blanca diseñada por Lance Wyman para los Juegos Olímpicos de 1968, ahora sobre fondo rojo, corona el monumento situado en El Zócalo, en un impresionante y disputado entorno de edificios formado por el Templo Mayor, el principal templo azteca de Tenochtitlán, la Catedral Metropolitana de la Ciudad de México y el Palacio Nacional, sede del Poder Ejecutivo de México. Fotografía de Sandra L. López Varela.

Su colocación no es un hecho aislado. La ola de violencia producida principalmente por el tráfico de drogas y la pobreza en México, que han cobrado miles de vidas durante las últimas dos décadas, ha llevado a los sobrevivientes a colocar monumentos en lugares estratégicos de la Ciudad de México, que denotan la interpretación pública de su historia. En busca de la justicia y la verdad, estos monumentos no buscan representar otra historia victimizadora que narre el sufrimiento de las víctimas, ni son tampoco un intento de señalar la existencia de un acto heroico, mucho menos su relevancia estética. La colocación de estos 
monumentos se opone a la "lógica social del espacio" (Hillier y Hanson) del gobierno mexicano, que evidencia la "complicidad inconsciente" de los curadores de monumentos nacionales en el arbitraje del conocimiento arqueológico como discurso político y las consecuencias que el mismo ha tenido para la construcción de la "verdad nacional" (ver Smith).

Los sobrevivientes quieren conocer el paradero de sus seres queridos y han decidido erigir su propio monumento para llorar a sus muertos (Derrida y Spire). Al erigir "antimonumentos" se construye un espacio que cuestiona la "verdad oficial" de una serie de acontecimientos, que culminaron con la desaparición o asesinato de sus seres queridos y por los cuales nadie ha sido llevado ante la justicia. Los antimonumentos se alzan desafiantes en espacios públicos, que expresan con fuerza relaciones históricas poderosas y controvertidas, o ante las instituciones que se cree son responsables de crímenes y negligencias. No debe sorprender que estos antimonumentos se sitúen, ante la indiferencia de las autoridades, principalmente a lo largo del Paseo de la Reforma, un bulevar cuyo trazo se inspiró en los Campos Elíseos de París, que conecta con uno de los barrios más pudientes de México y está flanqueado por los edificios modernos más altos del país, que albergan hoteles de cinco estrellas, bancos, lujosos restaurantes y negocios, galerías de arte e incluso la Embajada de Estados Unidos y la sede de la segunda bolsa de valores más grande de América Latina. Esta avenida es la expresión de la desigualdad estructural social y económica que rige en México y que, durante décadas, ha sido testigo de la resistencia, pues por ella han marchado movimientos sociales y manifestaciones políticas.

Cerca del exclusivo Hotel Four Seasons, las familias colocaron un antimonumento que representa a los 49 niños que murieron durante un incendio en la Guardería ABC, en junio de 2009, de la que era responsable el Instituto Mexicano del Seguro Social. Junto con el antimonumento colocado frente a la bolsa de valores de México, que simboliza a los 65 mineros que murieron a causa de una explosión de metano y cuyos cuerpos nunca fueron recuperados, ambos exhiben la negligencia de las instituciones federales y privadas y su nula observación a las mínimas normas de seguridad. Por su parte, el antimonumento que exige no olvidar a los 43 estudiantes de Ayotzinapa que desaparecieron el 26 de septiembre de 2014 (Figura 5), durante el gobierno del presidente Peña Nieto, encarna a los 
miles de inocentes que han desaparecido debido a una guerra ineficaz contra los cárteles de la droga, que han propagado corrupción y complicidad en todos los niveles de gobierno. Una declaración similar es el antimonumento que exige que se encuentre a los dos jóvenes secuestrados el 5 de enero de 2012, durante un viaje de cumpleaños que hacían por el oeste de México.

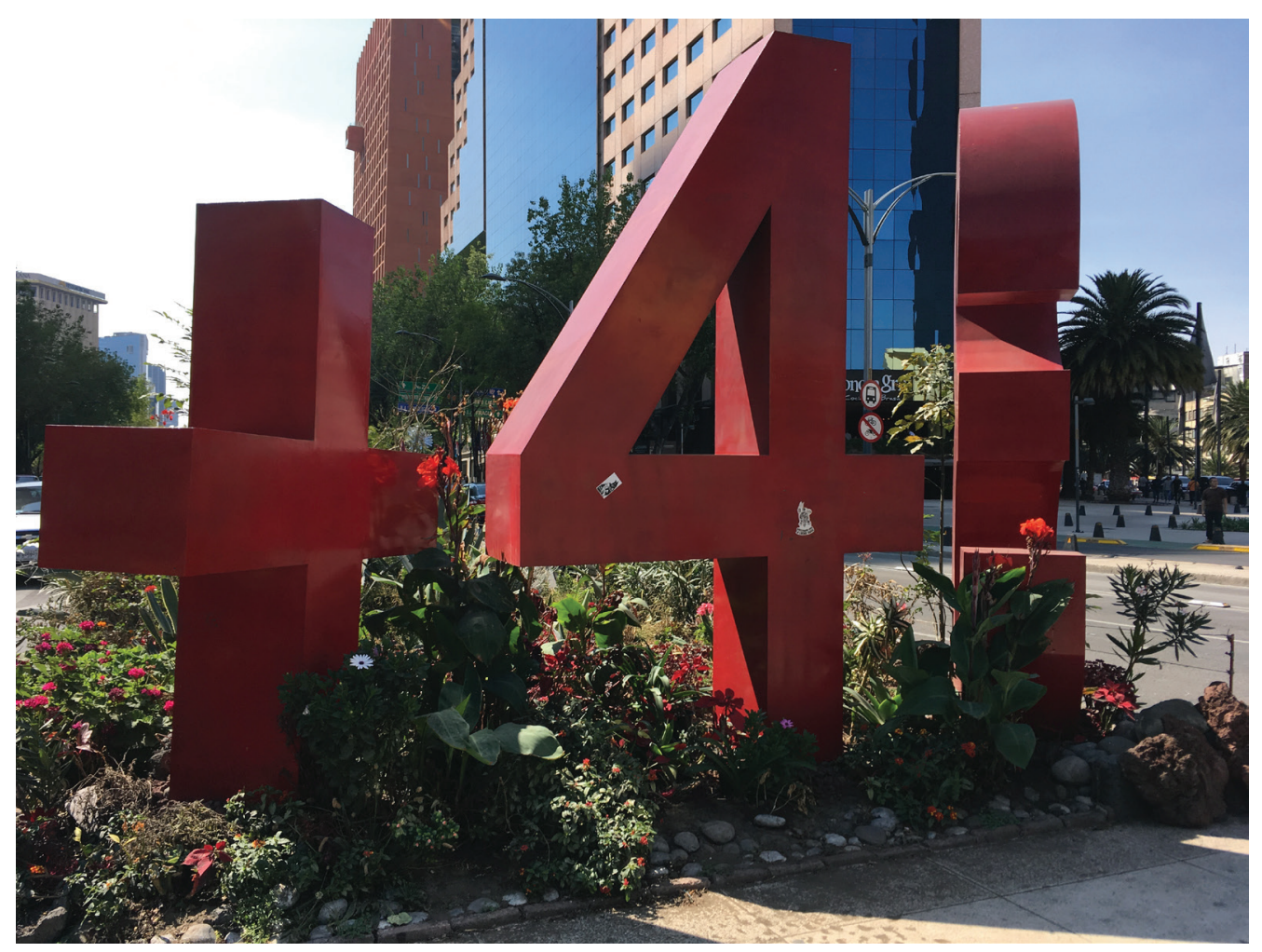

Figura 5. El "anti-monumento" dedicado a los 43 estudiantes de Ayotzinapa, que desaparecieron el 26 de septiembre de 2014. Fotografía de Sandra L. López Varela.

No podríamos estar más de acuerdo con Todorov en que el uso de la memoria literal nunca ha de traer justicia, que lo que hay que promover es la memoria ejemplar, aquella que muestra que el pasado debe permanecer en el presente por sus valores y su sentido de la justicia, a fin de evitar la repetición de errores y de que caiga en el olvido. La sociedad ha expresado de muchas maneras su desinterés por los monumentos dedicados a la memoria literal (López Varela, El patrimonio 
cultural) e incluso, el 2 de octubre de 2018, exigió que se retiraran las placas que conmemoraban al presidente Díaz Ordaz por toda la ciudad. La sociedad y sus antimonumentos expresan las injusticias históricas y contemporáneas, mas no como una novela épica de víctimas y héroes, como ha sido la narración oficial de lo acontecido en Tlatelolco el 2 de octubre de 1968.

La objetivación de la masacre como monumento (Assman y Czaplicka 130) revela la relación entre política y patrimonio cultural. Afirmamos aquí que la actual "política de la memoria" puede ser un mecanismo de apropiación estatal mucho más efectivo que las estrategias de "olvido" utilizadas anteriormente por el gobierno mexicano y que incluían el acceso controlado a archivos y testigos, así como su destrucción y desaparición (Casas y Flores Farfán). Declarar a Tlatelolco como patrimonio cultural intangible quizá no sea una acción tan calculada como se piensa y, por ello, debemos estar vigilantes ante la posibilidad que su apropiación pueda mermar la riqueza etico-política del movimiento al reducirla a un episodio de la historia de las resistencias. Es claro, sin embargo, que la memoria social es terca y, por ello, encontramos ahora una definición contracultural del patrimonio, que incluye la colocación de antimonumentos en lugares estratégicos para que todos sepan que sus recuerdos no serán excluidos de la historia de México.

\section{Leticia Flores Farfán}

Doctora en Filosofía. Profesora Titular de la Facultad de Filosofía y Letras de la unAM. Miembro del Sistema Nacional de Investigadores. Responsable del proyecto de investigación PAPIIT-UNAM "Cine y filosofia. Poéticas de la condición humana 2" y del proyecto PAPIME/UnAM "Filozoofía. Historia filosófica de los animales", del que se ha publicado los volúmenes correspondientes a la antigüedad, al renacimiento y modernidad. Su último libro es Vocablos griegos para un léxico de Filosofia política en donde analiza términos fundamentales como polis, nomos, stasis, philía. 
El pasado remasterizado: la posproducción del patrimonio cultural de México

\section{Sandra L. López Varela}

Doctora por la Universidad de Londres. Es profesora en la Facultad de Filosofía y Letras de la Universidad Nacional Autónoma de México. Su investigación actual se centran en los efectos de las políticas de desarrollo social y la economía institucional para combatir la pobreza con el apoyo de tecnologías no industriales. Recibió el Premio Friedrich Wilhelm Bessel de la Fundación Alexander von Humboldt en 2012. Ha dedicado esfuerzos para promover la aplicación antropología en México. Ha sido miembro de la Junta Ejecutiva de la Asociación Americana de Antropología (2011-2014), Presidenta de la Sociedad de Ciencias Arqueológicas (2009-2011), y es Tesorera interina de la Sociedad Mexicana de Antropología.

\section{Obras citadas}

Assman, Jan y John Czaplicka. "Collective Memory and Cultural Identity". New German Critique 65 (1995): 125-133. Impreso

Berger, Stefan. Writing the Nation, a Global Perspective. Nueva York: Palgrave Macmillan, 2007. Impreso.

Casas, Armando y Leticia Flores Farfán. "Entre memoria y olvido: el 2 de octubre de 1968" Revista Mexicana de Ciencias Políticas y Sociales 63.234 (2018): 201214. Web. < doi: http://dx.doi.org/10.22201/fcpys.2448492xe.2018.234.65717 >

Connerton, Paul. How Societies Remember. Cambridge: Cambridge University Press, 1989. Impreso

Secretaría de Cultura. Declaran a Tlatelolco Patrimonio Cultural Intangible por su valor en la memoria histórica. DF: Secretaría de Cultura, 2018. Web. $<$ https:// www.cultura.cdmx.gob.mx/comunicacion/nota/0994-18>

Deleuze, Gilles y Félix Guattari. "Mai 68 n'a pas eu lieu. Gilles Deleuze et Félix Guattari reprennent la parole ensemble pour anlayzer 1984 à la lumière de 1968". 
Chimeres 64 (2007): 23-24. Web. <https://www.cairn.info/revue-chimeres-2007-2-page-23.htm\#> Derrida, Jacques y Antoine Spire. Au-delà des apparences. Lormont: Éditions Le Bord de l'eau, 2002. Impreso.

Diario Oficial de la Federación. Acuerdo No. A/o19/o2. México: Procuraduría General de la República, 2002. Impreso.

Diario Oficial de la Federación. Ley Federal sobre Monumentos y Zonas Arqueológicos, Artísticos e Históricos. México: DOF, 2018. Impreso.

Flores Farfán, Leticia. "Tzvetan Todorov: Memoria y justicia" Figuras del Discurso III. La violencia, el olvido y la memoria. Ed. A. Villegas, N. Talavera, R. Monroy y L. de Mora. Cuernavaca: Bonilla - UAEmor, 2019. Impreso.

Fournier, Patricia y Jorge Martínez Herrera. "México, 1968: Among Olympic Fanfares, goverment, Repression and Genocide". Memories from Darkness, Archaeology of Repression and Resistance in Latin America. Ed. Pedro Funari, Andrés Zarankin y Melisa A. Salerno. Nueva York: Springer, 2009. 145-174. Web. $<10.1007 / 978-1-4419-0679-3 \_10>$

González de Alba, Luis. Tlatelolco aquella tarde. México: Cal y Arena, 2016. Impreso.

Halbwachs, Maurice. On Collective Memory. Chicago: Chicago University Press, 1992. Impreso

Harvey, David. "The political Economy of Public Space". The Politics of Public Space. Ed. Setha M. Low y Neil Smith. Nueva York: Routledge, 2006. 17-34. Impreso.

Hillier, Bill y Julianne Hanson. The Social Logic of Space. Cambridge: Cambridge University Press, 1984. Impreso.

Krauze, Enrique. México. Biografía del poder. México: Tusquets, 2017. Impreso

López Varela, Sandra L. "Mexico's Heritage". Encyclopedia of Global Archaeology. Ed. Claire Smith. Nueva York: Springer, 2014. 4872-7. Web. < https://doi. org/10.1007/978-1-4419-0465-2_2291>

López Varela, Sandra L. "Cultural Heritage and the Digital Divide". Copy Culture. Sharing in the Age of Digital Reproduction. Ed. Brendan Cormier. Gales: V\&A Publishing y Fundación Peri, 2018. 149-157. Impreso 
El pasado remasterizado: la posproducción del patrimonio cultural de México

López Varela, Sandra L. "When your country has history and people have memory" Anthropology News. 23 de enero 2019. Web. <http://www.anthropology-news. org/index.php/2019/01/23/when-your-country-has-history-and-people-havememor>

Low, Setha M. Spatializing Culture, The Ethnography of Space and Place. Nueva York: Routledge, 2017. Impreso.

Meskell, Lynn. "Sites of Violence: Terrorism, Tourism, and Heritage in the Archeological Present". Contemporary Archaeology in Theory, the New Pragmatism. Ed. Robert W. Preucel y Stephen A. Mrozowski. Malden, MA: Wiley-Blackwell 2010. 508-524. Impreso.

Misztal, Barbara A. Theories of Social Remembering. Maidenhead: Open University Press, 2003. Impreso

Monsiváis, Carlos.. El 68 La tradición de la resistencia. México: Era, 2008. Impreso.

Montemayor, Carlos. Rehacer la historia. Análisis de los nuevos documentos del 2 de octubre de 1968 en Tlatelolco. México: Planeta, 200o. Impreso

Nora, Pierre. 1989. "Entre la memoria y la historia: Les Lieux de Mémoire". Representaciones 26: 7-24. Web.

Poniatowska, Elena. La noche de Tlatelolco, testimonios de historia oral. México: Era, 1972. Impreso.

Portevin, Catherine y Tzvetan Todorov. Devoirs et Délices. Une vie de passeur. Entretiens avec Catherine Portevin. París: Éditions du Seuil, 2002. Impreso

Fiscalía Especial Ignacio Carrillo Prieto. "Informe oficial sobre la "Guerra Sucia" de México, el gobierno reconoce responsabilidad por masacres, tortura, desapariciones y genocidio". 2006. 209. Impreso.

Ralph, Sarah. Archaeology of Violence, The: Interdisciplinary Approaches. Albany, NY: State University of New York Press, 2012. Impreso.

Scherer García, Julio y Carlos Monsiváis. Parte de guerra: Tlatelolco 1968. Documentos del general Marcelino García Barragán. Los hechos y la historia. México: Nuevo Siglo, 1999. Impreso. 
Leticia Flores Farfán y Sandra L. López Varela

Schroeder Cordero, Francisco Arturo. "Legislación protectora de los monumentos y zonas de monumentos en México". Memoria del III Congreso de Historia del Derecho Mexicano. Ciudad de México: UnaM, 1983. Impreso

Smith, Laurajane. Archological Theory and the Politics of Cultural Heritage. Nueva York: Routledge, 2004. Impreso.

Smith, Laurajane. Use of Heritage. Londres: Routledge. 2006. Impreso.

Smith, Laurajane. "Empty Gestures? Heritage and the Politics of Recognition". Cultural Heritage and Human Rights. Ed. Helaine Silverman y Fairchild Ruggles,. Nueva York: Springer, 2007. 159-171. Web. < https://link.springer.com/chapter/10.1007/978-0-387-71313-7_9>

Sørensen, Marie Louise Stig y Dacia Viejo-Ros. War and Cultural Heritage. Biographies of Place. Nueva York: Cambridge University Press, 2015. Impreso.

Starzmann, Maria Theresia, Susan Pollock y Reinhard Bernbeck. "Imperial Inspections: Archaerology, War and Violence". Archaeologies: Journal of the world archaeological congress 4.3 (2008): 353-355. Web.

Todorov, Tzvetan. Les abus de la mémoire. París: Arléa, 1995. Impreso

Todorov, Tzvetan. Facing The Extreme: Moral Life in the Concentration Camps. Nueva York: Metropolitan Books, 1996. Impreso

Todorov, Tzvetan. The Conquest of America: The Question of the Other. Norman: University of Oklahoma Press, 1999. Impreso.

Todorov, Tzvetan. Mémoire du mal, tentation du bien : Enquête sur le siècle. París: Éditions Robert Laffont S.A, 200o. Impreso.

Todorov, Tzvetan. Hope and Memory: Lessons from the Twentieth Century. Nueva Jersey: Princeton University Press, 2003. Impreso

Todorov, Tzvetan. "Memory as Remedy for Evil". Journal of International Criminal Justice 7.3 (2009): 447-462. Web. <DoI: https://doi.org/10.1093/jicj/mqpo17>

UNESCO. Indicadores UNESCO de cultura para el desarrollo: manual metodológico. París: Organización de las Naciones Unidas para la Educación, la Ciencia y la Cultura, 2014. Web. <https://unesdoc.unesco.org/ark:/48223/pfoooo229609> 
El pasado remasterizado: la posproducción del patrimonio cultural de México

unesco. Textos fundamentales de la Convención para la Salvaguardia del Patrimonio Cultural Inmaterial de 2003, edición 2018. París: UNESCO, 2018. Web. <https://unesdoc.unesco.org/ark:/48223/pfoooo265942_spa?posInSe$\mathrm{t}=1$ \&queryId=952ec 537 -adaf- $44 \mathrm{db}-\mathrm{a} 3$ ae-ad25e9a9cefo $>$

Wilson, Ross J. 2019. "Heritage and Politics". The Encyclopedia of Archaeological Sciences. Ed. Sandra L. López Varela. Malden: Wiley- Blackwell, 2019. 819-823 Web. <DOI: https://doi.org/10.1002/9781119188230.saseaso285> 